Article

\title{
Lattice Site of Rare-Earth Ions in Stoichiometric Lithium Niobate Probed by $\mathrm{OH}^{-}$ Vibrational Spectroscopy
}

\author{
László Kovács * (D), Laura Kocsor, Zsuzsanna Szaller, Ivett Hajdara, Gabriella Dravecz, \\ Krisztián Lengyel and Gábor Corradi \\ Institute for Solid State Physics and Optics, Wigner Research Centre for Physics, Hungarian Academy \\ of Sciences, Budapest, Konkoly-Thege M. út 29-33. H-1121, Hungary; kocsor.laura@wigner.mta.hu (L.K.); \\ szaller.zsuzsanna@wigner.mta.hu (Z.S.); hajdara.ivett@wigner.mta.hu (I.H.); \\ dravecz.gabriella@wigner.mta.hu (G.D.); lengyel.krisztian@wigner.mta.hu (K.L.); \\ corradi.gabor@wigner.mta.hu (G.C.) \\ * Correspondence: kovacs.laszlo@wigner.mta.hu; Tel.: +36-1-392-2588
}

Academic Editor: Shujun Zhang

Received: 7 July 2017; Accepted: 21 July 2017; Published: 25 July 2017

\begin{abstract}
Rare-earth $\left(\mathrm{RE}=\mathrm{Er}^{3+}, \mathrm{Nd}^{3+}\right.$, or $\left.\mathrm{Yb}^{3+}\right)$ ion-doped stoichiometric $\mathrm{LiNbO}_{3}$ crystals were grown by the Czochralski and the high-temperature top-seeded solution growth methods. For the $0.22-0.87 \mathrm{~mol} \%$ concentration range of the RE oxides in the melt/solution, in addition to the well-known hydroxyl $\left(\mathrm{OH}^{-}\right)$vibrational band in undoped stoichiometric $\mathrm{LiNbO}_{3}$, a new infrared absorption band was observed at about $3500 \mathrm{~cm}^{-1}$, similar to the case of the trivalent optical damage resistant (ODR) dopants $\mathrm{In}^{3+}$ and $\mathrm{Sc}^{3+}$. By comparing the frequencies and polarization dependences of the bands to those detected for ODR ion containing crystals, they are attributed to the stretching vibration of $\mathrm{OH}^{-}$ions in $\mathrm{RE}^{3+} \mathrm{Nb}^{-} \mathrm{OH}^{-}$complexes. Consequently, above a given concentration threshold, some of the rare-earth ions are assumed to occupy niobium sites in the $\mathrm{LiNbO}_{3}$ lattice. The same model is also suggested for RE-doped congruent $\mathrm{LiNbO}_{3}$ crystals containing over-threshold ( $>5 \mathrm{~mol} \%$ ) amounts of the Mg-co-dopant.
\end{abstract}

Keywords: IR spectroscopy; lithium niobate; hydroxyl ions; rare-earth dopants

\section{Introduction}

Point defects influencing the physical properties of lithium niobate crystals have been the subject of a vast number of papers presented since their first growth in 1960's [1]. Hydroxyl ions $\left(\mathrm{OH}^{-}\right)$always present in $\mathrm{LiNbO}_{3}$ crystals grown in air have proved to be excellent probes of crystal defects [2]. The $\mathrm{OH}^{-}$stretching vibration frequency and the shape of the corresponding absorption band significantly depend on the ion's surroundings. This fact has allowed for a long series of defect studies: the compositional changes in the crystal ( $\mathrm{Li} / \mathrm{Nb}$ ratio) [3], the changed incorporation of a number of dopants above a threshold concentration [4], and quite recently the trapping of polarons in the $\mathrm{OH}^{-}$ion's immediate vicinity [5] were able to be investigated in considerable detail.

The structure of $\mathrm{LiNbO}_{3}$ at room temperature belongs to the trigonal $\mathrm{R} 3 \mathrm{c}$ space group [6]. The oxygen arrangement can be described as distorted hexagonal close packing. Along the ferroelectric axis, the cation sequence in the oxygen octahedra is $\mathrm{Li} \mathrm{Nb} \mathrm{V}_{\mathrm{i}} \mathrm{Li} \mathrm{Nb} \mathrm{V}_{\mathrm{i}}$, where $\mathrm{V}_{\mathrm{i}}$ denotes an empty octahedron. In contrast to stoichiometric $\mathrm{LiNbO}_{3}(\mathrm{sLN})$ with $\mathrm{Li} / \mathrm{Nb}=1$, its congruent counterpart (cLN) with $\mathrm{Li} / \mathrm{Nb} \approx 0.945$ contains high amounts of intrinsic defects such as antisite niobium ions $(\mathrm{Nb}$ on $\mathrm{Li}$ site, $\left.\mathrm{Nb}_{\mathrm{Li}}\right)$ and their charge-compensating lithium vacancies $\left(\mathrm{V}_{\mathrm{Li}}\right)$, which modify the cation sequence. 
SLN crystals have a number of specific properties not shown by cLN [7]. This comes first of all from the strongly reduced number of intrinsic defects. Dopants are often used to obtain new or improved capabilities of the crystal. Among them, rare-earth ions (RE) are introduced to $\mathrm{LiNbO}_{3}$ to serve as laser activators [8] or, more recently, as active scattering centers in coherent quantum optical experiments [9]. Their spectroscopic properties in sLN significantly differ from those observed in cLN; in particular, the linewidths of the optical absorption and luminescence signals are much narrower, due to the more regular crystal structure of sLN [10].

It is well-known that the optical damage resistance of $\mathrm{LiNbO}_{3}$ can be increased by special dopants called ODR ions, like $\mathrm{Mg}^{2+}, \mathrm{Zn}^{2+}, \mathrm{In}^{3+}, \mathrm{Sc}^{3+}, \mathrm{Hf}^{4+}, \mathrm{Zr}^{4+}$, and $\mathrm{Sn}^{4+}$ (see, e.g., Ref. [7] and references therein). Above a threshold concentration that depends on crystal stoichiometry and the valence state of the dopants, the photorefractive damage is strongly suppressed. While this concentration is in the range of several (2-7) $\mathrm{mol} \%$ for cLN it is usually only $0.1-0.2 \mathrm{~mol} \%$ for closely stoichiometric $\mathrm{LiNbO}_{3}[4,7]$. According to the widely-accepted defect model, $\mathrm{Nb}_{\mathrm{Li}}$ ions are absent in over-threshold $\mathrm{LN}$ and the ODR dopants, incorporating only at Li sites below the threshold, start occupying also $\mathrm{Nb}$ sites.

In undoped stoichiometric $\mathrm{LiNbO}_{3}$ crystals $(\mathrm{Li} / \mathrm{Nb}=1)$, a single narrow absorption band (full width at half maximum, FWHM $<3 \mathrm{~cm}^{-1}$ ) can be observed at $300 \mathrm{~K}$ at about $3466 \mathrm{~cm}^{-1}$ due to the stretching vibration of hydroxyl ions [3]. Theoretical ab initio calculations showed this band to belong to an $\mathrm{OH}^{-}$ion substituting for an $\mathrm{O}^{2-}$ ion close to a $\mathrm{Li}$ vacancy [11]. In nearly stoichiometric $\mathrm{LiNbO}_{3}$ $(\mathrm{Li} / \mathrm{Nb} \approx 1)$, a weak satellite band appears at about $3480 \mathrm{~cm}^{-1}$ and an even weaker one at about $3490 \mathrm{~cm}^{-1}$, attributed to some remaining defects related to non-stoichiometry (e.g., $\mathrm{Nb}_{\mathrm{Li}}$ and /or $\mathrm{V}_{\mathrm{Li}}$ ) perturbing the hydroxyl vibration [3]. In stoichiometric or nearly stoichiometric crystals containing ODR dopants above the photorefractive threshold concentration new $\mathrm{OH}^{-}$absorption bands appear at vibrational frequencies between 3470 and $3540 \mathrm{~cm}^{-1}$, depending on the valence state of the dopants [4]. These bands have been attributed to the vibration of hydroxyl ions in defect complexes containing the ODR dopants at $\mathrm{Nb}$ sites $\left(\mathrm{M}^{\mathrm{n}+}{ }_{\mathrm{Nb}}-\mathrm{OH}^{-}\right.$, where $\mathrm{M}^{\mathrm{n}+}=\mathrm{Mg}^{2+}, \mathrm{Zn}^{2+}, \mathrm{In}^{3+}, \mathrm{Sc}^{3+}, \mathrm{Hf}^{4+}, \mathrm{Zr}^{4+}$ or $\left.\mathrm{Sn}^{4+}\right)$ that are charge compensated by $\mathrm{M}^{\mathrm{n}+} \mathrm{Li}$ ions. In $\mathrm{Mg}^{2+}+\mathrm{RE}^{3+}$ and $\mathrm{Mg}^{2+}+\mathrm{TR}^{3+}$ double-doped cLN (where $\mathrm{TR}^{3+}=\mathrm{Fe}^{3+}$ or $\mathrm{Cr}^{3+}$ transition metal ions), additional $\mathrm{OH}^{-}$bands have been observed between 3500 and $3525 \mathrm{~cm}^{-1}$ and interpreted as hydroxyl vibration in defect complexes where the second dopant occupies a $\mathrm{Nb}$ site $[12,13]$. To our knowledge, no systematic investigations of the hydroxyl defects have been carried out for double-doped stoichiometric $\mathrm{LN}$ crystals. Rare examples are $\mathrm{Mg}^{2+}+\mathrm{Nd}^{3+}$ and $\mathrm{Zn}^{2+}+\mathrm{Nd}^{3+}$ doped near-sLN $[14,15]$ where no $\mathrm{OH}^{-}$band corresponding to the presence of $\mathrm{Nd}^{3+}$ has been detected, and $\mathrm{Mg}^{2+}+\mathrm{Er}^{3+}$ doped sLN [16] where the $\mathrm{OH}^{-}$band at about $3489 \mathrm{~cm}^{-1}$ has been attributed to an $\mathrm{Er}^{3+} \mathrm{Li}-\mathrm{OH}^{-}$defect. In $\mathrm{RE}^{3+}$-doped $\mathrm{cLN}$, apart from the well-known broadened intrinsic $\mathrm{OH}^{-}$band at about $3485 \mathrm{~cm}^{-1}$, no dopant-related additional $\mathrm{OH}$-bands have been reported.

In the present work, sLN crystals doped only with $\mathrm{RE}^{3+}$ ions have been investigated using $\mathrm{OH}^{-}$ vibrations as a probe of dopant incorporation to test assumptions concerning threshold behavior and defect models of RE dopants. The obtained results are discussed based on the comparison with previous experimental findings for both $\mathrm{RE}$ and ODR ion doped $\mathrm{LiNbO}_{3}$.

\section{Experimental}

$\mathrm{Er}^{3+}, \mathrm{Yb}^{3+}$ or $\mathrm{Nd}^{3+}$ doped sLN crystals were grown by the high-temperature top-seeded solution growth (HTTSSG) method [3], using a computer controlled resistance heated crystal growth apparatus from flux containing $\mathrm{Nb}_{2} \mathrm{O}_{5}, \mathrm{Li}_{2} \mathrm{O}, \mathrm{K}_{2} \mathrm{O}$, and $\mathrm{RE}_{2} \mathrm{O}_{3}$, with molar ratios $\left[\mathrm{K}_{2} \mathrm{O}\right] /\left[\mathrm{Nb}_{2} \mathrm{O}_{5}\right]=0.31$, $\left[\mathrm{Li}_{2} \mathrm{O}\right] /\left[\mathrm{Nb}_{2} \mathrm{O}_{5}\right]=1$ and $\left[\mathrm{RE}_{2} \mathrm{O}_{3}\right] /\left[\mathrm{Nb}_{2} \mathrm{O}_{5}\right]$ between $0.001-0.02$; therefore, the amount of $\mathrm{RE}$ oxides in the flux was between 0.04 and $0.87 \mathrm{~mol} \%$, with the upper limit well above the expected threshold concentrations for trivalent ODR ions in sLN. $\mathrm{Nb}_{2} \mathrm{O}_{5}$ Starck LN grade, $\mathrm{Li}_{2} \mathrm{CO}_{3}$ Alfa Puratronic, $\mathrm{K}_{2} \mathrm{CO}_{3}$ Merck p.a. and $\mathrm{RE}_{2} \mathrm{O}_{3}$ Alfa Puratronic were used as raw materials. Crystals were grown along the $\mathrm{Z}$ direction with a diameter of $16 \mathrm{~mm}$. The pulling and rotation rates were $0.1 \mathrm{~mm} / \mathrm{h}$ and $20-40 \mathrm{rpm}$, respectively. $\mathrm{Yb}^{3+}$ and $\mathrm{Nd}^{3+}$ doped sLN crystals were also grown by the Czochralski method, starting 
from melt characterized by $\mathrm{Li} / \mathrm{Nb}=1.38$. Both the HTTSSG and Czochralski techniques resulted in nearly stoichiometric crystals with $\mathrm{Li} / \mathrm{Nb}$ ratio close to 1 , as determined by the method described in Ref. [17]. In both cases, the crystals were grown in air at about $1050-1250{ }^{\circ} \mathrm{C}$, allowing for the incorporation of hydroxyl ions [2].

Table 1 lists the rare-earth doped crystals grown for the experiments. Beside the concentration of $\mathrm{RE}_{2} \mathrm{O}_{3}$ in $\mathrm{mol} \%$, the [RE]/[Nb] molar ratio in the solution/melt is also given to facilitate an easy comparison with the RE concentration in the crystal which is given in atomic\% relative to the number of $\mathrm{LiNbO}_{3}$ molecules (it is practically equal to the $[\mathrm{RE}] /[\mathrm{Nb}] \times 100$ ratio in the crystal). The real Er content incorporated in the lattice has been determined by two independent methods: (i) the transition strength for the ${ }^{4} \mathrm{I}_{15 / 2}{ }^{4} \mathrm{I}_{13 / 2}$ transition at $6529 \mathrm{~cm}^{-1}$ taken from Ref. [18] has been used to calculate the Er concentration from the absorption spectrum measured at $300 \mathrm{~K}$, and (ii) a high-resolution continuum source flame atomic absorption spectrometer (HR-CS-FAAS, ContrAA-700, Analytik Jena AG, Jena, Germany) has been applied using pneumatic nebulization of the solutions obtained by the digestion of the crystal samples, as described in detail in Ref. [19]. The two methods supplied very similar data within a factor of two for all four crystals. In spite of some scattering of the atomic absorption spectroscopic data due to the inhomogeneities of the crystals, a saturation of the Er content could be observed as a function of the Er concentration in the solution for both methods. Such saturation has been reported for the incorporation of Er into cLN crystals at a much higher doping level [20]. The concentrations of the $\mathrm{Er}^{3+}$ ions in our sLN crystals listed in Table 1 are averages of the values obtained by the two methods. The incorporation of $\mathrm{Yb}^{3+}$ and $\mathrm{Nd}^{3+}$ ions has also been checked by measuring the transition strengths for the ${ }^{2} \mathrm{~F}_{5 / 2}$ and ${ }^{4} \mathrm{I}_{13 / 2}$ excited levels, respectively, and a behavior essentially similar to that of the Er dopant has been observed.

Oriented (Z-cut) samples of about 3-5 mm thickness were prepared both for RE and hydroxyl absorption measurements. The crystals were placed in the vacuum chamber of a BRUKER IFS 66v/S FTIR spectrophotometer (Ettlingen, Germany) to avoid interference with the surrounding water molecules. The spectra were recorded in transmission mode at $300 \mathrm{~K}$ with a resolution of $0.5 \mathrm{~cm}^{-1}$. The polarization dependence was measured on $Y$-cut samples using a KRS- 5 wire grid polarizer (Graseby Specac, Orpington, England).

Table 1. Concentrations of rare-earth oxides in the solution or in the melt (all dopants) and in the crystal (given only for $\mathrm{Er}$ in atomic\% relative to the number of $\mathrm{LiNbO}_{3}$ molecules).

\begin{tabular}{|c|c|c|c|c|c|}
\hline $\begin{array}{c}\mathrm{RE}^{3+} \\
\text { Dopant }\end{array}$ & $\begin{array}{l}\text { Growth } \\
\text { Method }\end{array}$ & $\begin{array}{l}\mathrm{RE}_{2} \mathrm{O}_{3} \text { Concentration in } \\
\text { the Solution/Melt [mol\%] }\end{array}$ & $\begin{array}{l}{[\mathrm{RE}] /[\mathrm{Nb}] \text { Molar Ratio in }} \\
\text { the Solution/Melt }\left(\times 10^{-2}\right)\end{array}$ & $\begin{array}{l}\text { Er Concentration in } \\
\text { the Crystal [Atomic\%] }\end{array}$ & $\begin{array}{c}\mathrm{RE}^{3+}{ }_{\mathrm{Nb}}-\mathrm{OH}^{-} \\
\text {Frequency }\left[\mathrm{cm}^{-1}\right]\end{array}$ \\
\hline Er & HTTSSG & 0.05 & 0.1 & 0.24 & - \\
\hline $\mathrm{Er}$ & HTTSSG & 0.22 & 0.5 & 0.37 & 3487 \\
\hline Er & HTTSSG & 0.43 & 1 & 0.54 & 3488 \\
\hline $\mathrm{Er}$ & HTTSSG & 0.87 & 2 & 0.55 & 3488 \\
\hline $\mathrm{Yb}$ & HTTSSG & 0.04 & 0.1 & & - \\
\hline $\mathrm{Yb}$ & HTTSSG & 0.09 & 0.2 & & - \\
\hline $\mathrm{Yb}$ & HTTSSG & 0.44 & 1 & & 3494 \\
\hline $\mathrm{Yb}$ & HTTSSG & 0.86 & 2 & & 3494 \\
\hline $\mathrm{Yb}$ & Czochralski & 0.85 & 2 & & 3495 \\
\hline $\mathrm{Nd}$ & HTTSSG & 0.44 & 1 & & 3513,3517 \\
\hline $\mathrm{Nd}$ & Czochralski & 0.85 & 2 & & 3518 \\
\hline
\end{tabular}

\section{Results and Discussion}

Figure 1 shows the $\mathrm{OH}^{-}$absorption spectra of sLN crystals doped with various amounts of erbium. At low concentrations $\left(0.24\right.$ atomic $\left.\% \mathrm{Er}^{3+}\right)$ the spectrum resembles that of the undoped crystal, with the main absorption band peaking at about $3466 \mathrm{~cm}^{-1}$ with two satellites at $\approx 3480$ and $\approx 3490 \mathrm{~cm}^{-1}$, as described above. At about 0.4-0.5 atomic\% nominal Er concentration, a new $\mathrm{OH}^{-}$ absorption band appears at about $3488 \mathrm{~cm}^{-1}$. The sum of the new and the main band corresponds to the full number of $\mathrm{OH}^{-}$molecules in the crystal, which may vary from sample to sample. The higher the erbium concentration in the crystal, the more intense the absorption band found at $3488 \mathrm{~cm}^{-1}$. 
An $\mathrm{OH}^{-}$absorption band at $3489.4 \mathrm{~cm}^{-1}$ has already been detected for an $0.5 \mathrm{~mol} \% \mathrm{Er}_{2} \mathrm{O}_{3}$-doped sLN crystal grown by the Czochralski method from a melt containing $59 \mathrm{~mol} \% \mathrm{Li}_{2} \mathrm{CO}_{3}$ and $41 \mathrm{~mol} \%$ $\mathrm{Nb}_{2} \mathrm{O}_{5}$ [16]. Though the method of crystal growth was different from ours, the $\mathrm{OH}^{-}$band observed seems to be the same. The vibrational frequency of the new $\mathrm{OH}^{-}$band is close to those observed in trivalent ODR ion doped sLN crystals at $3505 \mathrm{~cm}^{-1}$ for $\mathrm{In}^{3+}$ and Sc${ }^{3+}$ [4]. New bands have also been observed for the other two rare-earth ion-doped sLN crystals, at $3494 \mathrm{~cm}^{-1}$ for $\mathrm{Yb}^{3+}$ and at 3513-3518 $\mathrm{cm}^{-1}$ for $\mathrm{Nd}^{3+}$ as seen in Figure 2. While the $\mathrm{OH}^{-}$bands for $\mathrm{Yb}^{3+}$ doped sLN grown by the Czochralski and HTTSSG methods were similar, the $\mathrm{Nd}^{3+}$ doped crystal grown by the HTTSSG technique showed a double $\mathrm{OH}$ peak, which will be discussed later. The observed $\mathrm{OH}^{-}$vibrational frequencies of the RE doped sLN crystals fit into the general decreasing trend found earlier for ODR ion doped sLN with increasing valence state of the dopants (see Figure 3a).

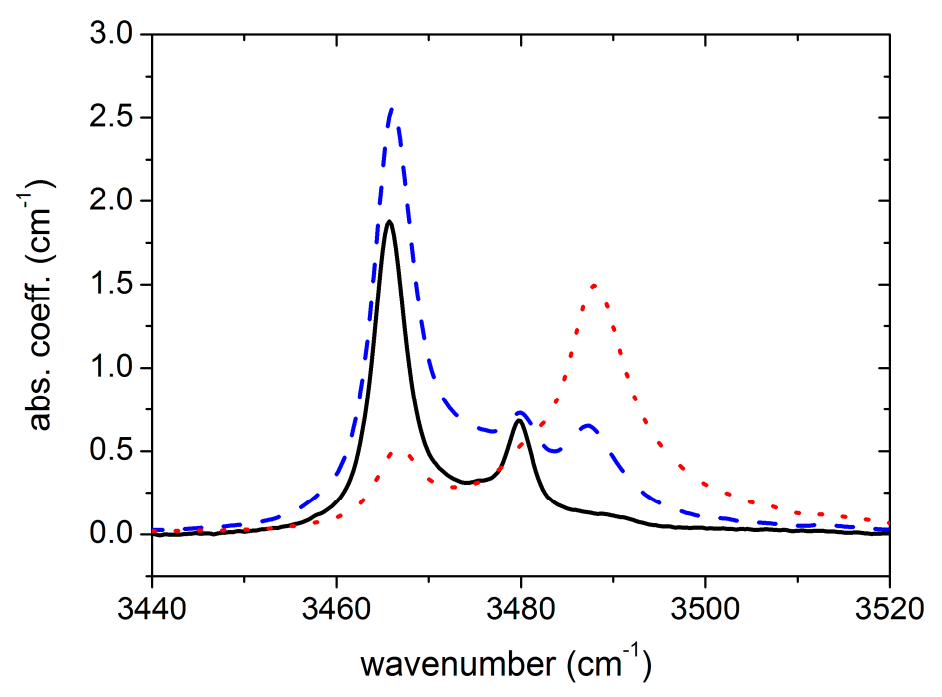

Figure 1. $\mathrm{OH}^{-}$absorption spectra of sLN crystals containing various amounts of Er (black continuous 0.24 atomic $\%$, blue dashed 0.37 atomic $\%$, and red dotted 0.54 atomic $\%$ ). The full $\mathrm{OH}^{-}$content slightly varied from sample to sample.

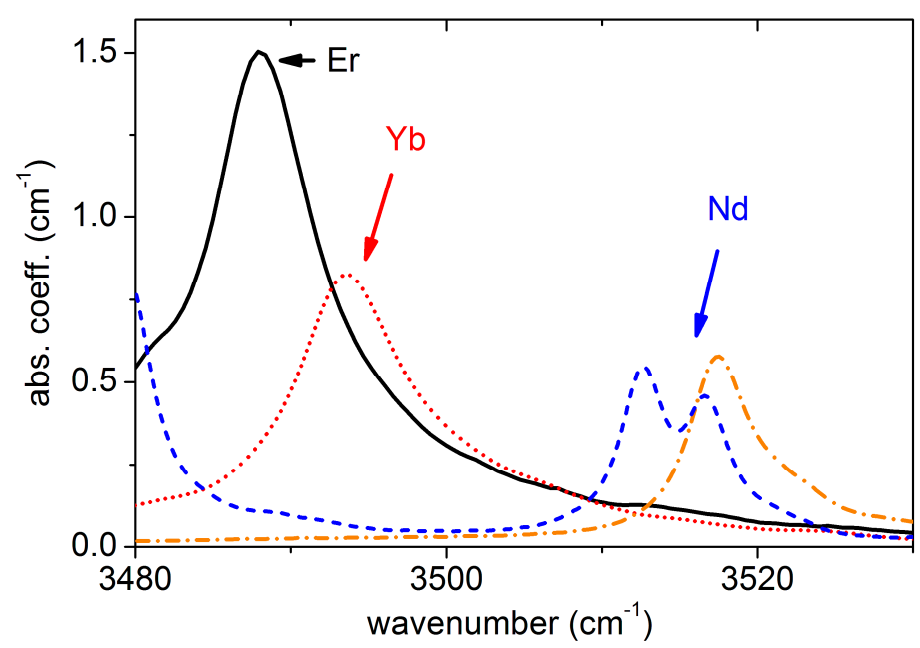

Figure 2. $\mathrm{OH}^{-}$absorption bands in sLN crystals grown with $\approx 0.44 \mathrm{~mol} \% \mathrm{RE}_{2} \mathrm{O}_{3}$ (black continuous $\mathrm{Er}$, red dotted $\mathrm{Yb}$, and blue dashed $\mathrm{Nd}$ ). The Czochralski grown sLN doped with $0.85 \mathrm{~mol} \% \mathrm{Nd}_{2} \mathrm{O}_{3}$ is also shown (orange dash-dot). 


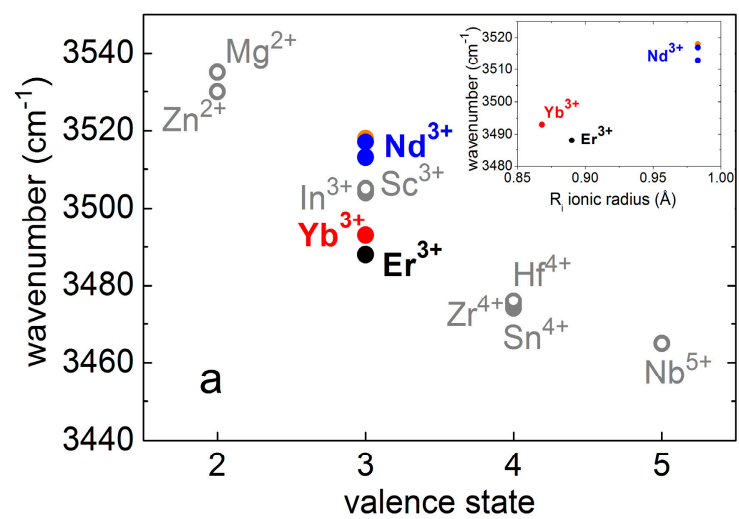

(a)

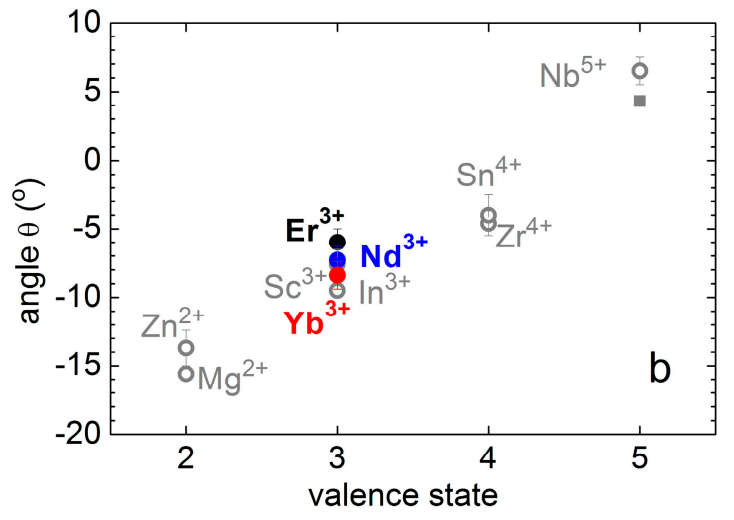

(b)

Figure 3. (a) Vibrational frequencies of the $\mathrm{OH}^{-}$ions in rare-earth doped sLN crystals together with those observed for ODR ion doped sLN [4]. The inset shows the vibrational frequency of the $\mathrm{OH}^{-}$ion as a function of the ionic radius of the $\mathrm{RE}^{3+}$ dopant. (b) The angle $\theta$ between the $\mathrm{O}-\mathrm{H}$ dipole and the oxygen plane perpendicular to the $\mathrm{Z}$ axis of the $\mathrm{LiNbO}_{3}$ crystal.

From the polarization dependence of the $\mathrm{OH}^{-}$band, the direction of the $\mathrm{O}-\mathrm{H}$ dipole can be determined with respect to the oxygen plane perpendicular to the ferroelectric $Z$ axis of LN crystals. As an example, the polarization dependence of the intensity of the new band observed in $\mathrm{Yb}$-doped sLN crystals is shown in Figure 4, where alpha is the angle between the oxygen plane perpendicular to the $\mathrm{Z}$ axis and the electric field vector $\mathrm{E}$ of the incident light. The angle $\theta$ between the $\mathrm{O}-\mathrm{H}$ bond and the oxygen plane can be determined from the $a_{x} / a_{Z}$ absorbance ratio using Equation (1) from Ref. [21]:

$$
\mathrm{ax}_{\mathrm{X}} / \mathrm{az}_{\mathrm{Z}}=1 / 2 \cot ^{2} \theta
$$

Fitting this equation to the experimental data, the angle $\theta_{3493}=8.4^{\circ}$ has been obtained. This value, together with $\theta_{3488}=6^{\circ}$ and $\theta_{3518}=8^{\circ}$ determined for the $\mathrm{O}-\mathrm{H}$ bond in the $\mathrm{Er}^{3+}$ and $\mathrm{Nd}^{3+}$ doped sLN crystal, respectively, follow the trend observed for the ODR ions, as shown in Figure $3 \mathrm{~b}$.

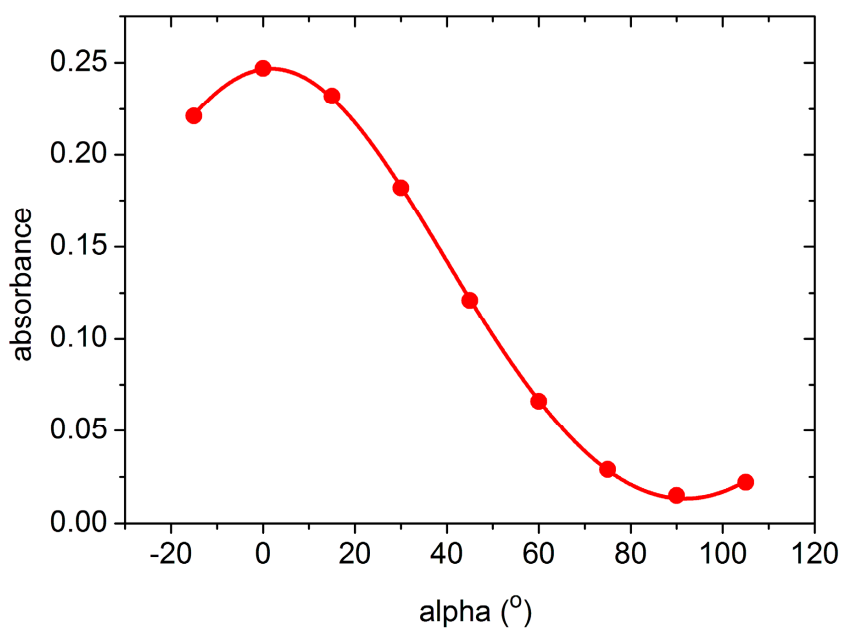

Figure 4. Angular dependence of the amplitude of the $\mathrm{OH}^{-}$absorption band at $3494 \mathrm{~cm}^{-1}$ in 1 atomic\% $\mathrm{Yb}$-doped sLN crystal (dots are experimental points, the solid line is a fitted curve using the function taken from Ref. [21]).

The excellent fit of both vibrational frequency and $\mathrm{O}-\mathrm{H}$ bond angle to the trend already observed for ODR ions in sLN:RE as a function of valence state suggests that the $\mathrm{OH}^{-}$ions in sLN:RE form 
similar defect complexes to those in ODR ion doped sLN crystals, i.e., the hydroxyl ions are close to the rare-earth ions occupying $\mathrm{Nb}$ site $\left(\mathrm{RE}^{3+} \mathrm{Nb}^{-} \mathrm{OH}^{-}\right)$. A schematic drawing of the defect complex is shown in Figure 5: the rare-earth ion occupies a $\mathrm{Nb}$ site while the proton is bound to an oxygen shared by two octahedra containing in turn a structural and a $\mathrm{Li}$ vacancy, the $\mathrm{O}-\mathrm{H}$ bond being directed along a bisector plane of the oxygen triangle and tilted by about 6-8 degrees out of the oxygen plane towards the structural vacancy.

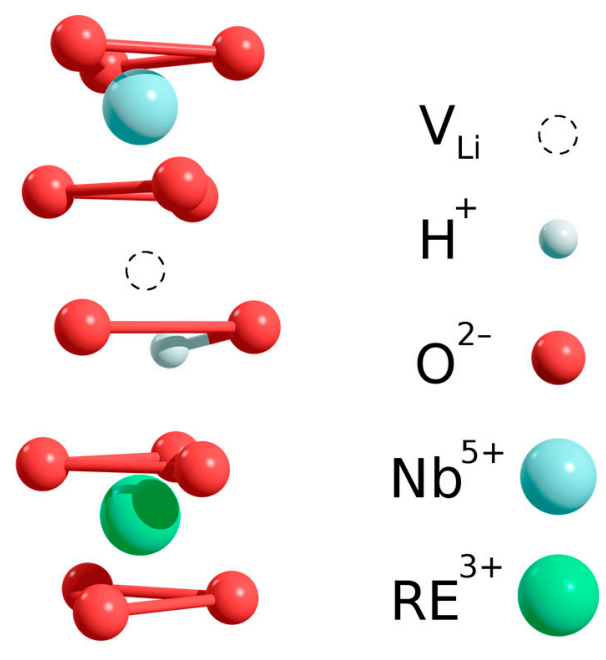

Figure 5. Schematic drawing of the $\mathrm{RE}^{3+} \mathrm{Nb}^{-} \mathrm{OH}^{-}$defect complex: the rare-earth ion substitutes niobium, the proton is bound to an oxygen shared by two octahedra "containing", in turn, a structural and $\mathrm{Li}^{+}$vacancy; the $\mathrm{O}-\mathrm{H}$ bond is directed along a bisector plane of the oxygen triangle and tilted by about 6-8 degrees out of the oxygen plane towards the structural vacancy.

These $\mathrm{RE}^{3+}{ }_{\mathrm{Nb}}-\mathrm{OH}^{-}$complexes are present in sLN crystals above a given concentration of rare-earth dopants (threshold effect), as has also been observed for ODR ions. This concentration for rare-earth ions is similar to the threshold value for ODR ions, i.e., several tenths of atomic\% in sLN crystals [4]. For rare-earth ions, the term "threshold" possibly doesn't mean a photorefractive damage threshold, but implies the concentration of the dopant above which the rare-earth ions can occupy $\mathrm{Nb}$ sites in the lattice. The threshold concentration can hardly be determined more precisely, since the dopants present in the melt or solution during growth may diversely influence the actual $\mathrm{Li} / \mathrm{Nb}$ ratio; accordingly, the crystal cannot be regarded as perfectly stoichiometric any more. The extent of non-stoichiometry can also vary for different RE dopants. In any case, we stick to the assumption that the new $\mathrm{OH}^{-}$bands appear in the crystal when the rare-earth dopants start to occupy $\mathrm{Nb}$ sites. Due to the missing positive charges (compared to the perfect lattice) the $\mathrm{RE}^{3+}{ }_{\mathrm{Nb}}$ defect attracts protons, i.e., $\mathrm{RE}^{3+} \mathrm{Nb}^{-} \mathrm{OH}^{-}$complexes can easily be formed. Since the hydroxyl ion concentration $(\approx 10-100 \mathrm{ppm}[2])$ is typically lower by orders of magnitude than the rare-earth concentration in these crystals, only a small proportion of the incorporated rare-earth ions are involved in the complex; the others are assumed to preferentially occupy Li sites, as is generally concluded from results obtained by other techniques [7] (a trend valid for other dopants as well). It should be noted that both $\mathrm{OH}^{-}$bands (those which characterize the undoped and heavily RE-doped crystals) can be seen in the absorption spectra of the sLN crystals grown from flux containing $0.44 \mathrm{~mol} \% \mathrm{RE}$ oxides. It can be assumed that $\mathrm{OH}^{-}$ centers preferentially associate with $\mathrm{RE}^{3+} \mathrm{Nb}$ ions, as already shown for LN:Mg in [22], so the amount of $\mathrm{RE}^{3+}$ on $\mathrm{Nb}$ sites may be estimated to be of the same order as the $\mathrm{OH}^{-}$content of these samples.

Although the vibrational frequencies of the hydroxyl ions in $\mathrm{RE}^{3+} \mathrm{Nb}^{-} \mathrm{OH}^{-}$complexes follow the trend observed for ODR ions as shown in Figure 3a, their values differ by about $20-30 \mathrm{~cm}^{-1}$. This difference may come from the different ionic radii of the rare-earth ions. The frequencies of $\mathrm{OH}^{-}$ forming complexes with erbium or ytterbium having similar ionic radii ( 0.89 and $0.87 \AA$, respectively) 
are close to each other, but for the large $\mathrm{Nd}^{3+}$ ion $(\mathrm{r}=0.98 \AA)$ [23] the $\mathrm{OH}^{-}$vibrational frequencies are significantly higher. This can qualitatively be understood taking into account the longer O-O distances in the oxygen octahedron containing the large $\mathrm{Nd}^{3+}$ ion and the concomitant smaller extension of the nearby oxygen octahedra, resulting in a stronger $\mathrm{O}-\mathrm{H}$ bond which can increase the vibrational frequency.

It is interesting to compare our results with those observed for cLN crystals double-doped with $\mathrm{Mg}$ and RE ions [12]. Similarly to sLN:RE, no antisite niobium ions are present in cLN:Mg+RE with $\mathrm{Mg}$ concentrations above the threshold, and the $\mathrm{RE}^{3+}$ ions are expected to also enter $\mathrm{Nb}$ sites, forming $\mathrm{RE}^{3+}{ }_{\mathrm{Nb}}-\mathrm{OH}^{-}$complexes. Indeed, such $\mathrm{OH}^{-}$bands were detected in double-doped cLN at about $3491 \mathrm{~cm}^{-1}$ for $\mathrm{Mg}+\mathrm{Er}$ and $3522 \mathrm{~cm}^{-1}$ for $\mathrm{Mg}+\mathrm{Nd}$ [12]. At that time, however, IR spectrometers with grating monochromators were used with less accurate wavenumber calibrations than the FTIR spectrometers applied nowadays. Taking into account the position of the $\mathrm{Mg}-\mathrm{OH}$ bands found at about $3538 \mathrm{~cm}^{-1}$ earlier [12] and at $3536 \mathrm{~cm}^{-1}$ more recently [4], a correction by $2 \mathrm{~cm}^{-1}$ to lower wavenumbers should also be necessary for the other bands. Accordingly, the $\mathrm{OH}^{-}$bands for $\mathrm{Er}$ and $\mathrm{Nd}$ in double-doped cLN have to be assumed to be at about 3489 and $3520 \mathrm{~cm}^{-1}$, respectively, which is in relatively good agreement with our present results $\left(3488\right.$ and $3518 \mathrm{~cm}^{-1}$ ). The re-measurement of the $\mathrm{Mg}+\mathrm{Nd}$ and $\mathrm{Mg}+\mathrm{Er}$ co-doped cLN crystals fully confirmed our correction. This agreement, however, has a serious consequence for the previous model [12], assuming O-H stretching vibrations in $\mathrm{Mg}^{2+} \mathrm{Li}^{-} \mathrm{OH}^{-}-\mathrm{RE}^{3+} \mathrm{Nb}$ complexes. In fact, our recent results show that the $\mathrm{OH}^{-}$absorption bands in double-doped cLN, similar to single $\mathrm{RE}^{3+}$-doped sLN, originate from $\mathrm{OH}^{-}$ions in $\mathrm{RE}^{3+}{ }_{\mathrm{Nb}}-\mathrm{OH}^{-}$ defects without $\mathrm{Mg}$, as was pointed out by Kong et al. [24] based on their nuclear magnetic resonance measurements. In fact, an additional charge compensator like $\mathrm{Mg}_{\mathrm{Li}}$ in the imminent neighborhood of the $\mathrm{RE}^{3+} \mathrm{Nb}^{-} \mathrm{OH}^{-}$complex might result in a measurable shift of the $\mathrm{OH}^{-}$vibration frequency, as suggested by the pronounced sensitivity of the latter to the charge of adjacent cations as displayed by Figure 3a.

As shown in Figure 2, a two-component band peaking at 3513 and $3517 \mathrm{~cm}^{-1}$ has been observed in $\mathrm{Nd}^{3+}$ doped sLN grown by the HTTSSG method, in contrast to the Czochralski grown crystal. The reason for this splitting is not yet known; it may originate from the existence of non-equivalent $\mathrm{Nd}$ centers at $\mathrm{Nb}$ sites, similar to the case of below-threshold systems, where $\mathrm{Nd}$ ions were reported to occupy various off-centered Li sites with non-equivalent local environments [25]. A high number of non-equivalent centers have also been reported for Er [25-27] or $\mathrm{Yb}[25,28,29]$ doped LN crystals due to the presence of various charge compensating defects in the neighborhood of the dopants occupying $\mathrm{Li}$ sites. Similar non-equivalent local environments may also be present for $\mathrm{Er}$ and $\mathrm{Yb}$ sitting on $\mathrm{Nb}$ sites in our highly doped sLN crystals, resulting in broadening and the appearance of some shoulders of the $\mathrm{OH}^{-}$vibrational bands seen in Figure 2.

\section{Conclusions}

Rare-earth ion-doped sLN crystals have been successfully grown by the Czochralski using high-temperature top-seeded solution growth techniques. Above several tenths of atomic $\% \mathrm{RE}^{3+}$ ion content, new $\mathrm{OH}^{-}$absorption bands appeared and were attributed to the presence of $\mathrm{RE}^{3+}-\mathrm{OH}^{-}$ type defects in the crystals. The same model is also suggested for overthreshold $\mathrm{Mg}+\mathrm{RE}$ co-doped cLN. The O-H vibrational frequency and bond direction in the $\mathrm{RE}^{3+}-\mathrm{OH}^{-}$complexes are similar to those in $\mathrm{M}^{3+} \mathrm{Nb}^{-} \mathrm{OH}^{-}$defects in ODR ion-doped sLN, indicating that part of the $\mathrm{RE}^{3+}$ ions occupy $\mathrm{Nb}$ sites. This part, however, could be very small, since the hydroxyl ion concentration in the crystal is much less than the $\mathrm{RE}^{3+}$ concentration. Moreover, the $\mathrm{OH}^{-}$ions prefer to form complexes with $\mathrm{M}^{3+}{ }_{\mathrm{Nb}}$ more than with $\mathrm{Nb}^{5+}{ }_{\mathrm{Nb}}$, therefore the amounts of $\mathrm{M}^{3+}{ }_{\mathrm{Nb}}$ and $\mathrm{OH}^{-}$ions are in the same order of magnitude. Those methods that are less sensitive to minority fractions of dopants in the crystal (e.g., EXAFS, RBS, etc.) may still find them essentially on Li sites without detecting a small portion occupying $\mathrm{Nb}$ positions. Our results reaffirmed that $\mathrm{OH}^{-}$ions are very sensitive probes of the defect structure in $\mathrm{LiNbO}_{3}$ crystals. 
Acknowledgments: The author K. Lengyel was supported by a János Bolyai research fellowship of the Hungarian Academy of Sciences.

Author Contributions: L.K. conceived and performed the FTIR experiments, analyzed the data and wrote the paper; L.K. and Z.S. grew the crystals; I.H. prepared the samples; G.D. performed the chemical analysis; K.L. and G.C. analyzed the data.

Conflicts of Interest: The authors declare no conflict of interest. The founding sponsors had no role in the design of the study; in the collection, analyses, or interpretation of data; in the writing of the manuscript, and in the decision to publish the results.

\section{References}

1. Nassau, K.; Levinstein, H.J.; Loiacono, G.M. Ferroelectric lithium niobate 1. Growth, domain structure, dislocations and etching. J. Phys. Chem. Solids 1966, 27, 983-988. [CrossRef]

2. Wöhlecke, M.; Kovács, L. OH ${ }^{-}$ions in oxide crystals. Crit. Rev. Solid State 2001, 26, 1-86. [CrossRef]

3. Polgár, K.; Péter, Á.; Kovács, L.; Corradi, G.; Szaller, Z. Growth of stoichiometric $\mathrm{LiNbO}_{3}$ single crystals by top seeded solution growth method. J. Cryst. Growth 1997, 177, 211-216. [CrossRef]

4. Kovács, L.; Szaller, Z.; Lengyel, K.; Corradi, G. Hydroxyl ions in stoichiometric $\mathrm{LiNbO}_{3}$ crystals doped with optical damage resistant ions. Opt. Mater. 2014, 37, 54-58. [CrossRef]

5. Freytag, F.; Corradi, G.; Imlau, M. Atomic insight to lattice distortions caused by carrier self-trapping in oxide materials. Sci. Rep. 2016, 6, 36929. [CrossRef] [PubMed]

6. Abrahams, S.C.; Reddy, J.M.; Bernstein, J.L. Ferroelectric lithium niobate 3. Single crystal X-ray diffraction study at $24^{\circ}$ C. J. Phys. Chem. Solids 1966, 27, 997-1012. [CrossRef]

7. Lengyel, K.; Péter, Á.; Kovács, L.; Corradi, G.; Pálfalvi, L.; Hebling, J.; Unferdorben, M.; Dravecz, G.; Hajdara, I.; Szaller, Z.; et al. Growth, defect structure and THz application of stoichiometric lithium niobate. Appl. Phys. Rev. 2015, 2, 040601/1-28. [CrossRef]

8. Kaminskii, A.A. Laser Crystals, 2nd ed.; Springer: Berlin/Heidelberg, Germany; New York, NY, USA; London, UK; Paris, France; Tokyo, Japan; Hong Kong, China, 1990; pp. 210-212.

9. Sun, Y.; Thiel, C.W.; Cone, R.L.; Equall, R.W.; Hutcheson, R.L. Recent progress in developing new rare earth materials for hole burning and coherent transient applications. J. Lumin. 2002, 98, 281-287. [CrossRef]

10. Malovichko, G.; Grachev, V.; Schirmer, O. Interrelation of intrinsic and extrinsic defects-Congruent, stoichiometric, and regularly ordered lithium niobate. Appl. Phys. B 1999, 68, 785-793. [CrossRef]

11. Szalay, V.; Lengyel, K.; Kovács, L.; Timón, V.; Hernández-Laguna, A. Vibrations of $\mathrm{H}^{+}\left(\mathrm{D}^{+}\right)$in stoichiometric $\mathrm{LiNbO}_{3}$ single crystal. J. Chem. Phys. 2011, 135, 124501/1-19. [CrossRef] [PubMed]

12. Kovács, L.; Rebouta, L.; Soares, J.C.; da Silva, M.F.; Hage-Ali, M.; Stoquert, J.P.; Siffert, P.; Sanz-Garcia, J.A.; Corradi, G.; Szaller, Z.; et al. On the lattice site of trivalent dopants and the structure of $\mathrm{Mg}^{2+}-\mathrm{OH}^{-}-\mathrm{M}^{3+}$ defects in $\mathrm{LiNbO}_{3}: \mathrm{Mg}$ crystals. J. Phys-Condens. Matter 1993, 5, 781-794. [CrossRef]

13. Feng, X.Q.; Ying, J.F.; Wu, Y.A.; Liu, J.C. A new $\mathrm{OH}^{-}$absorption band in $\mathrm{LiNbO}_{3}$ crystal. Chin. Sci. Bull. 1991, 36, 297-300.

14. Nakamura, M.; Sekita, M.; Takekawa, S.; Kitamura, K. Crystal growth and characterization of Nd, Mg co-doped near-stoichiometric $\mathrm{LiNbO}_{3}$. J. Cryst. Growth 2006, 290, 144-148. [CrossRef]

15. Babu Reddy, J.N.; Ganesh Kamath, K.; Vanishri, S.; Bhat, H.L.; Elizabeth, S. Influence of Nd:Zn codoping in near-stoichiometric lithium niobate. J. Chem. Phys. 2008, 128, 244709/1-10. [CrossRef] [PubMed]

16. Lee, S.M.; Shin, T.I.; Kim, Y.T.; Habu, M.; Ito, T.; Natori, M.; Yoon, D.H. Effect of optical properties of $\mathrm{Er}_{2} \mathrm{O}_{3}$ doped stoichiometric $\mathrm{LiNbO}_{3}$ single crystals and co-doped with MgO. Mater. Sci. Eng. B 2003, 105, $34-36$. [CrossRef]

17. Dravecz, G.; Kovács, L. Determination of the crystal composition from the $\mathrm{OH}^{-}$vibrational spectrum in lithium niobate. Appl. Phys. B 2007, 88, 305-307. [CrossRef]

18. Amin, J.; Dussardier, B.; Schweizer, T.; Hempstead, M. Spectroscopic analysis of $\mathrm{Er}^{3+}$ transitions in lithium niobate. J. Lumin. 1996, 69, 17-26. [CrossRef]

19. Bencs, L.; György, K.; Kardos, M.; Osán, J.; Alföldy, B.; Varga, I.; Ajtony, Z.; Szoboszlai, N.; Stefánka, Z.; Széles, É.; et al. Determination of trace elements in lithium niobate crystals by solid sampling and solution-based spectrometry methods. Anal. Chim. Acta 2012, 726, 1-8. [CrossRef] [PubMed]

20. Bermúdez, V.; Serrano, M.D.; Tornero, J.; Diéguez, E. Er incorporation into congruent $\mathrm{LiNbO}_{3}$ crystals. Solid State Commun. 1999, 112, 699-703. [CrossRef] 
21. Turrell, G. Infrared and Raman Spectra of Crystals; Academic Press: London, UK; New York, NY, USA, 1972; p. 156.

22. Lengyel, K.; Kovács, L.; Péter, Á.; Polgár, K.; Corradi, G.; Baraldi, A.; Capelletti, R. Thermal kinetics of $\mathrm{OH}^{-}$ ions in $\mathrm{LiNbO}_{3}: \mathrm{Mg}$ crystals above the photorefractive threshold. Appl. Phys. Lett. 2010, 96, 191907/1-3. [CrossRef]

23. Shannon, R.D. Revised Effective Ionic Radii and Systematic Studies of Interatomic Distances in Halides and Chalcogenides. Acta Cryst. A 1976, 32, 751-767. [CrossRef]

24. Kong, Y.; Xu, J.; Zhang, W.; Zhang, G. The site occupation of protons in lithium niobate crystals. J. Phys. Chem. Solids 2000, 61, 1331-1335. [CrossRef]

25. García Solé, J.; Bausá, L.E.; Jaque, D.; Montoya, E.; Murieta, H.; Jaque, F. Rare earth and transition metal ion centers in $\mathrm{LiNbO}_{3}$. Spectrochim. Acta A 1998, 54, 1571-1581. [CrossRef]

26. Gill, D.M.; Wright, J.C.; McCaughan, L. Site characterization of rare-earth-doped $\mathrm{LiNbO}_{3}$ using total site selective spectroscopy. Appl. Phys. Lett. 1994, 64, 2483-2485. [CrossRef]

27. Dierolf, V.; Koerdt, M. Combined excitation-emission spectroscopy of $\mathrm{Er}^{3+}$ ions in stoichiometric $\mathrm{LiNbO}_{3}$ : The site selectivity of direct and up conversion excitation processes. Phys. Rev. B 2000, 61, 8043-8052. [CrossRef]

28. Bodziony, T.; Kaczmarek, S.M. New low symmetry centres of $\mathrm{Yb}^{3+}$ impurities in lithium niobate single crystals. Opt. Mater. 2007, 29, 1440-1446. [CrossRef]

29. Malovichko, G.; Bratus, V.; Grachev, V.; Kokanyan, E. Electron paramagnetic resonance and electron-nuclear double resonance of nonequivalent $\mathrm{Yb}^{3+}$ centers in stoichiometric lithium niobate. Phys. Status Solidi (b) 2008, 246, 215-225. [CrossRef]

(C) 2017 by the authors. Licensee MDPI, Basel, Switzerland. This article is an open access article distributed under the terms and conditions of the Creative Commons Attribution (CC BY) license (http:/ / creativecommons.org/licenses/by/4.0/). 